\title{
Diabetic Predecessors: A factor leading to diabetes in successors
}

\section{Manju Dewan}

Assistant Professor, Post Graduate Department of Zoology, DAV College, Sector 10, Chandigarh

\section{ABSTRACT}

Type 2 diabetes has several causes: genetics and lifestyle are the most important ones. A combination of these factors can cause insulin resistance. Diabetes is a complex condition. Several factors must come together to develop type 2 diabetes. In the total population of 2048 subjects, 558 subjects had the positive family history of diabetes. Out of 558 subjects 12 (2.15\%) subjects were found to have impaired glucose level, 12 (2.15\%) subjects have already developed diabetes and both have family history diabetes in first degree relatives (Father, Mother, Father Mother both). In the present study, 558 (27.3\%) subjects have shown positive family history for diabetes.

KEY WORDS: TYPE 2 DIABETES, FAMILY HISTORY, FATHER, MOTHER

\section{INTRODUCTION}

Heredity plays an important role in determining the susceptibility to diabetes mellitus. Diabetes mellitus is multifactor in its etiology.A significantly greater frequency of diabetes has been found in close blood relatives of diabetic than in other population.Prevalence of overweight and obesityweremore in children with family history of diabetes and obesity.Environmental factors play a major role in the development of diabetes. Environmental risks factors known to influence the development of obesity and type 2 diabetes due to sedentary lifestyle, wrong eating habits and stress. Other nutritional fac-

\section{ARTICLE INFORMATION:}

*Corresponding Author: manjudewan72@gmail.com Received $12^{\text {th }}$ Oct, 2017

Accepted after revision $19^{\text {th }}$ Dec, 2017

BBRC Print ISSN: 0974-6455

Online ISSN: 2321-4007 CODEN: USA BBRCBA

Thomson Reuters ISI ESC and Crossref Indexed Journal

NAAS Journal Score 2017: 4.31 Cosmos IF: 4.006

- A Society of Science and Nature Publication, 2017. All rights reserved.

Online Contents Available at: http//www.bbrc.in/

DOI: $10.21786 / \mathrm{bbrc} / 10.4 / 15$ tors and toxins may also play a crucial role (Adeghate et al, 2006). These environmental factors clearly play a major role in the development of diabetes, but they do not impact everyone in the same way (Omar 2013). Family history of diabetes (FHD) and lifestyle are associated with type 2 diabetes (Yanyan et al, 2017). Nina et al, 2016 also found that children had a strong family history of cardiovascular disease and diabetes. The estimated risk for the diagnosis of type 2 diabetes (T2DM) increases approximately by 2-4 times, when father, mother or both have this condition. Conversely, many T2DM patients have family members with DM (Papazafiropoulou et al, 2017). The modern generalization of 
sedentary life and caloric abundance has created new physiological conditions capable of changing the level of expression of a number of genes involved in fuel metabolism and body weight regulation.

\section{MATERIALS AND METHODS}

2048 children had undergone questionnaire and dietary survey and health examination. Out of these, 1017 were from urban population and 1031 from rural population Children and adolescent aged 10-19 years were selected randomly for questioning regarding the different aspects of epidemiology and their health examination was done. The permission from parents of the children, undergoing examination and questionnaire survey was also taken on the self designed consent form.The Centers for Disease Control and Prevention (CDC) suggests two levels of concern for children based on the BMI-for-age charts.

At the 85th percentile and above, children are "at risk for overweight". At the 95th percentile or above, they are "overweight". The cutoff for underweight of less than the 5th percentile is based on recommendations by the World Health Organization Expert Committee on Physical Status 1998. The diagnostic criteria for diabetes mellitus have been modified from those previously recommended by WHO (1985).Revised criteria from the report of the expert committee on the diagnosis and classification of Diabetes Mellitus (2003) was used for the diagnosis of diabetes. Same criterion was used by Holly et al, 2003, Jung-Nan et al, 2003 and Reinehr (2013)

\section{RESULTS AND DISCUSSION}

Type 2 diabetes has several causes: genetics and lifestyle are the most important ones. A combination of these factors can cause insulin resistance. Diabetes is a complex condition. Several factors must come together to develop type 2 diabetes. For example, obesity and a sedentary lifestyle play a role. Genetics can also influence obesity and type 2 diabetes. Type 2 diabetes is caused by both genetic and environmental factors. Obesity has been attributed to various factors including genetics, environment, metabolism, behavior, personal history of obesity, culture, and socioeconomic status .In the total population of 2048 subjects, 558 subjects had the positive family history of diabetes. Out of 558 subjects 12 $(2.15 \%)$ subjects were found to have impaired glucose level, 12 (2.15\%) subjects have already developed diabetes and both have family history diabetes in first degree relatives (Father, Mother, Father Mother both) Table 1 and graphs $1 \mathrm{e} 2$.

The lifetime risk of developing type 2 diabetes is $40 \%$ for individuals who have one parent with type 2 diabetes

\begin{tabular}{|c|c|c|c|}
\hline & Father & Mother & \\
\hline All Data & $\begin{array}{|ll|}106 & 69.28 \\
\end{array}$ & $47 \quad 30.72$ & N.A.:1895 (92.53\%) \\
\hline \multicolumn{4}{|c|}{ FBG Categories } \\
\hline 1. $<110$ & & $102 \quad 70.83$ & $42 \quad 29.17$ \\
\hline 2. $110-126$ & $\begin{array}{|ll|}2 & 40.00\end{array}$ & 360.00 & \\
\hline \multirow{2}{*}{ 3. $>=126$} & 250.00 & 250.00 & Chi^2=2.88(df:2) \\
\hline & & & $C=0.14$ \\
\hline \multicolumn{4}{|c|}{ BMI Categories } \\
\hline 1. $<18.5$ & $195 \quad 54.78$ & 16145.22 & \\
\hline 2. $18.5-22.9$ & \begin{tabular}{|ll}
69 & 52.67 \\
\end{tabular} & $\begin{array}{|ll|}62 & 47.33 \\
\end{array}$ & \\
\hline 3. $23.0-24.9$ & $15 \quad 51.72$ & $\begin{array}{|ll|}14 & 48.28 \\
\end{array}$ & \\
\hline 4. $25.0-29.9$ & $15 \quad 45.45$ & $\begin{array}{ll}18 & 54.55 \\
\end{array}$ & \\
\hline \multirow[t]{2}{*}{ 5. $>30.0$} & $\begin{array}{ll}333.33 \\
\end{array}$ & 666.67 & Chi^2=2.62(df:4) \\
\hline & & & $\mathrm{C}=0.07$ \\
\hline \multicolumn{4}{|c|}{ BMI Categories } \\
\hline 1. $<18.5$ & $\begin{array}{|ll|}195 & 54.78 \\
\end{array}$ & 16145.22 & \\
\hline 2. $18.5-22.9$ & $\begin{array}{|ll|}69 & 52.67 \\
\end{array}$ & $\begin{array}{|ll|}62 & 47.33 \\
\end{array}$ & \\
\hline 3. $23.0-27.5$ & \begin{tabular}{|ll}
28 & 50.91 \\
\end{tabular} & \begin{tabular}{|ll}
27 & 49.09 \\
\end{tabular} & \\
\hline \multirow[t]{2}{*}{ 4. $>27.5$} & $\begin{array}{|ll|}5 & 31.25 \\
\end{array}$ & \begin{tabular}{|ll}
$11 \quad 68.75$ \\
\end{tabular} & Chi^2=3.58(df:3) \\
\hline & & & $\mathrm{C}=0.08$ \\
\hline \multicolumn{4}{|c|}{ Percentile Based } \\
\hline 1.Under Wt. & \begin{tabular}{|ll}
76 & 55.88 \\
\end{tabular} & \begin{tabular}{|ll}
60 & 44.12 \\
\end{tabular} & \\
\hline $\begin{array}{l}\text { 2.Healthy } \\
\text { Wt. }\end{array}$ & 18653.14 & 16446.86 & \\
\hline 3.At Risk & $24 \quad 60.00$ & \begin{tabular}{|ll}
16 & 40.00 \\
\end{tabular} & \\
\hline \multirow[t]{2}{*}{ 4.0ver Wt. } & $\begin{array}{|ll|}11 & 34.38 \\
\end{array}$ & \begin{tabular}{|ll}
$21 \quad 65.62$ \\
\end{tabular} & Chi^2=5.69(df:3) \\
\hline & & & $C=0.10$ \\
\hline \multicolumn{4}{|c|}{ W/H based (All) } \\
\hline 1.Normal & $255 \quad 52.80$ & \begin{tabular}{|ll}
228 & 47.20 \\
\end{tabular} & \\
\hline \multirow[t]{2}{*}{ 2.0ver Wt. } & $42 \quad 56.00$ & \begin{tabular}{|ll}
33 & 44.00 \\
\end{tabular} & Chi^2 $=0.27(\mathrm{df}: 1)$ \\
\hline & & & $\mathrm{C}=0.02$ \\
\hline
\end{tabular}

and $70 \%$ if both parents are affected. Type 2 diabetes are about 3 times more likely to develop the disease than individuals without a positive family history of the disease (Florez et al,2003). Type 2 diabetes itself is thought to be a polygenic disorder that develops due to complex interaction between multiple genes and environmental factors.For type 2 diabetes, risk for developing the disease is increased if a close family member (parent, sibling, or child) has type 2 diabetes or a medical condition being overweight or obese, having lipid abnormalities, or high blood pressure (Gibson, 2011).

In the present study, 558 (27.3\%) subjects have shown positive family history for diabetes.The increased prevalence of type 2 diabetes in the relatives of affected subjects is likely to reflect genetic predisposition to hyperglcaemia with additional affects from shared environment 


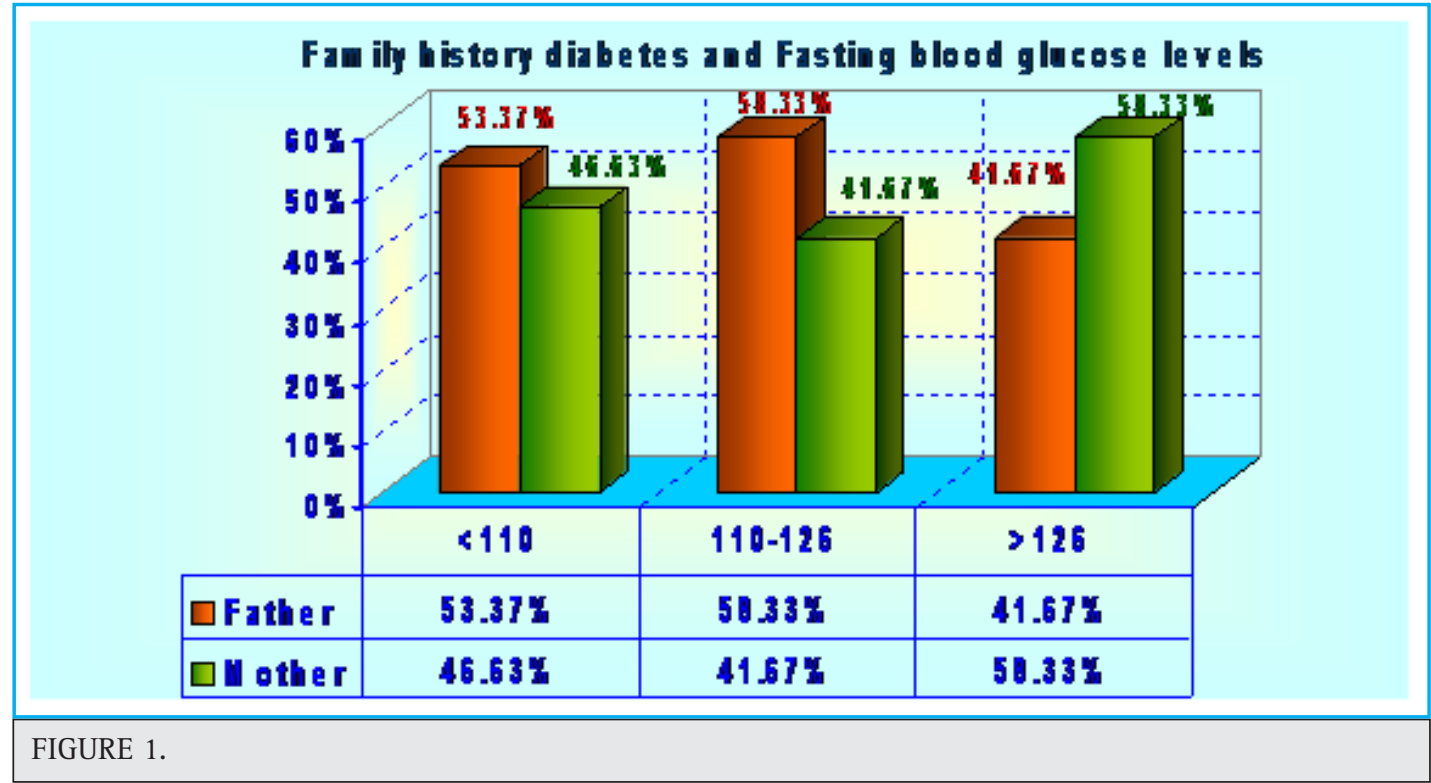

and life style (Shaw et al., 1999). Type 2 diabetes is recognized to arise from a combination of insulin resistance and impaired beta cell function. There are several reasons to consider that this could be particularly important in the obesity-diabetes field.(Ganada and Soeldner, 1987).

The first reason is that evolutionary forces may have shaped the human genome according to mechanisms (fat storage and mobilization, insulin secretion and sensitivity, leptin signaling, weight and body composition regulation, availability of glucose to the brain, etc.) that are now directly involved in the pathophysiology of juvenile obesity and associated changes in insulin-fuel homeostasis. These physiological functions and traits were of major importance during the infancy, childhood, and puberty of ancestors for metabolism, development, and growth. It is likely that prehistoric metabolic genes welcomed new mutations, provided that they favored the storage of calories. The notion of the thrifty genotype (Neel, 1962) covers all kinds of genes that could help early humans adapt to their hostile environment, when food was scarce and rather unpredictable, but nevertheless crucial for fitness and reproduction. It is likely that gene alleles favoring fat accumulation have been selected by humans and are now turning their bad effects to modern subjects because of an unexpected caloric richness and sedentary environment. Similarly, it is possible that insulin sensitivity underwent evolutionary changes toward increased channeling of glucose to

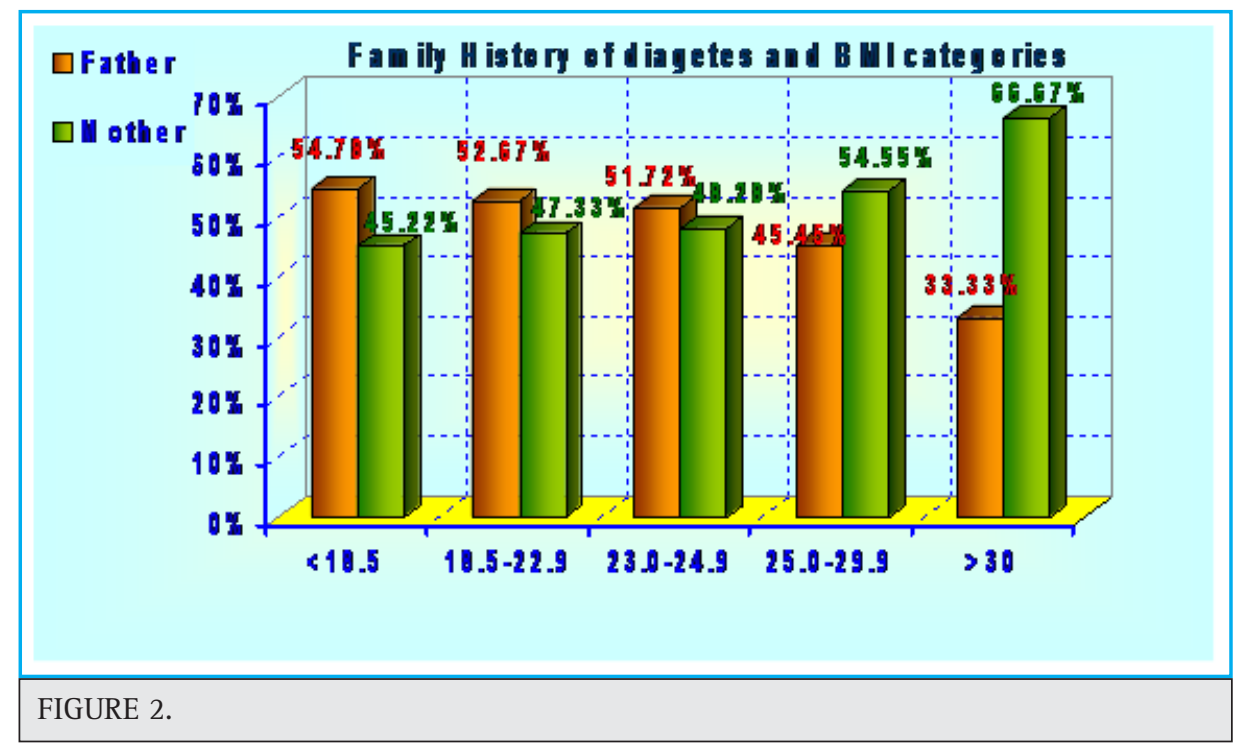

712 DIABETIC PREDECESSORS: A FACTOR LEADING TO DIABETES IN SUCCESSORS 
the large human brain rather than to the insulin-sensitive muscle mass. Measuring these phenomena early in life rather than in adulthood may more closely reflect their evolutionary tendencies. In addition, the life span of early humans was limited and evolution has therefore mostly worked on the physiology of young people (Boyd-Eaton et al 1988and Ritenbaugh,1989)

The study of young individuals meets the goals of predictive genetic epidemiology because it allows the follow-up of genotyped patients through later phenotype evolution as well as clinical trials (Le Stunff et al, 2001). It has recently been put forward that several fatderived cytokines, including the anti-inflammatory adiponectin, strongly modulate the risk of the metabolic syndrome and T2D associated with obesity (diabesity) (Lazar, 2006). Variation within the adiponectin gene is reported to modulate plasma levels of adiponectin and also to predict risk for diabesity and associated coronary heart diseases (Vasseur et al, 2003). Paradoxically, the adiponectin variant alleles that protect against the development of diabesity by maintaining high adiponectin concentrations also associate with obesity risk in both adults and obese children (Bouatia-Naji et al, 2003). Individuals with high adiponectin levels can be severely obese but seem to enjoy metabolic protection (Vasseur et al, 2005). In the general population, the same alleles, together with the type 2 diabetes protective PPAR-g 12Ala allele associates with a coronary heart disease protective risk factor pattern, elevated adiponectin and insulin sensitivity but also with a dramatic increase of 3 units of body mass index (Tanko et al, 2005).

People having a close relative with type 2 diabetes are at higher risk. There is also a strong inheritable genetic connection in type 2 diabetes: having relatives (especially first degree) with type 2 increases risks of developing this disease very substantially. In addition, there is also a mutation to the Islet Amyloid Polypeptide gene that results in an earlier onset, more severe, form of diabetes (Sakagashira, 1996). Developing type 2 diabetes is heavily influenced by environmental factors. Since our genetic code does not change significantly in one or two generations, the recent secular trend in diabetes must be due mostly to changes in the environment. Increased adiposity is the single most significant factor in the development of type 2 diabetes and the epidemics of obesity and type 2 diabetes largely parallel one another. The increasing prevalence of obesity is thought to be related primarily to changes in dietary habits and our increasingly sedentary lifestyle, though other factors (including toxins and infectious agents) may play a role. Genes may influence the risk of diabetes not only by directly altering insulin action or secretion, but also by altering how any given individual interacts with these environmental factors (Cho et al 2003).
However, environmental factors (almost certainly diet and weight) play a large part in the development of type 2 diabetes in addition to any genetic component. This can be seen from the adoption of the type 2 diabetes epidemiological pattern in those who have moved to a different environment as compared to the same genetic pool (Cotran and Collins, 1999).There is a stronger inheritance pattern for type 2 diabetes. Those with firstdegree relatives with type 2 diabetes have a much higher risk of developing type 2 diabetes, increasing with the number of those relatives. Concordance among monozygotic twins is close to $100 \%$, and about $25 \%$ of those with the disease have a family history of diabetes. Genes significantly associated with developing type 2 diabetes, include TCF7L2, PPARG, FTO, KCNJ11, NOTCH2, WFS1, CDKAL1, IGF2BP2, SLC30A8, JAZF1, and HHEX (Lyssenkoet al, 2008). KCNJ11 (potassium inwardly rectifying channel, subfamily J, member 11), encodes the islet ATP-sensitive potassium channel Kir6.2, and TCF7L2 (transcription factor 7-like 2) regulates proglucagon gene expression and thus the production of glucagonlike peptide-1 (Rother et al, 2007). Moreover, obesity (which is an independent risk factor for type 2 diabetes) is strongly inherited (National Diabetes InformationClearinghouse (NDIC), 2008).

Various hereditary conditions may feature diabetes, for example myotonic dystrophy and Friedreich's Ataxia. Wolfram's syndrome is an autosomal recessive neurodegenerative disorder that first becomes evident in childhood. It consists of diabetes insipidus, diabetes mellitus, optic atrophy and deafness, hence the acronym DIDMOAD (Barrett 2001). A major risk factor of type 2 diabetes mellitus (T2DM) is a positive family history of diabetes. In the present study it was found that family history of obesity was more likely to have more prevalence of obesity and overweight than those having family history of diabetes. This indicates that children having family history of obesity are more likely to become obese or over weight and diabetes.In the present study, subject having impaired glucose levels and diabetes have the positive family history in first degree relatives $4.3 \%$ subjects have the 1 st degree relatives in having impaired glucose level and diabetes. Children with type 2 diabetes usually have a family history of this disease. Of the patients, $74-100 \%$ have a first- or second-degree relative with type 2 diabetes (American Diabetes Association, 2000 and Arslanian, 2002). Of note, diabetes in the parent or other relative may not be recognized until the child is diagnosed. The high frequency of relatives with type 2 diabetes demonstrate the strong hereditary (likely multigenic) component to the disease (Kiess et al, 2003).

Papazafiropoulou et al, (2017) suggested that the likelihood of type 2 diabetes in the next generation is 
higher in the event of a diabetic mother than father. Both genetic factors, such as mitochondrial DNA mutations, and environmental components such as intrauterine environment, have been implicated in the higher maternal transmission of type 2 diabetes. Despite the above findings, some studies in populations with high frequency of type 2 diabetes have not corroborated the predominantly maternal transmission. Such works have shown either an excess paternal or an equal transmission of type 2 diabetes.

Studies of (Patel et al 2013) and Srikanth(2015) also showed that family history of diabetes was highly prevalent among type 2 diabetic patients.First degree relatives (FDR) of patients with type 2 diadetes were more insulin resistant and are reported to had larger abdominal subcutaneous adipocytes than adults without a family history (Anthanont et al, 2017). Among the type 2 patients in the study from Tamiln Naidu, $68.8 \%$ had a positive family history of type 2 diabetes and $31.2 \%$ had a negative family history. Family history of the study participants with type 2 diabetes was enumerated. Among the participants with positive family history of diabetes, $25.1 \%$ of them had diabetic mother, 15.3\% had diabetic father, $12.1 \%$ had both father and mother with diabetes, $47.4 \%$ of them had siblings with diabetes and $40 \%$ had family history of diabetes among second degree relatives such as grandparents, aunts and uncles (Geetha A et al. 2017)

\section{ACKNOWLEDGEMENT}

The author is highly thankful to UGC for providing grant for undertaking the research award.

\section{REFERENCES}

Adeghate E, Schattner P, Dunn E.2006. An update on the etiology and epidemiology of diabetes mellitus. Ann N Y Acad Sci. ;1084:1-29.

American Diabetes Association. 2000: Type 2 Diabetes in children and adolescents. Pediatrics; 105:671-680.

Anthanont P, P Ramos,, Jensen M D \& Hames K C.2017. Family history of type 2 diabetes, abdominal adipocyte size and markers of the metabolic syndrome International Journal of Obesity ; 41,1621-1626 (2017)

Arslanian S. 2002: Type 2 diabetes in children: clinical aspects and risk factors. HormRes; 57:19-28.

Barrett TG.2001. "Mitochondrial diabetes, DIDMOAD and other inherited diabetes syndromes". Best Practice \& Research. Clinical Endocrinology Et Metabolism; 15 (3): 325-43.

Bouatia-Naji N., MeyreD., Lobbens S., Seron K., Fumeron F., Balkau B., Heude B., Jouret B., Scherer P.E., Dina C., et al. 2006. $\mathrm{ACDC} /$ adiponectin polymorphisms are associated with severe childhood and adult obesity, Diabetes, vol. 55 (pg. 545-550)
Boyd-Eaton S, Konner M, Shostak M. 1988.: Stone-agers in the fast lane: chronic degenerative diseases in evolutionary perspective. Am J Med 84 :739 -749,

Center for Disease Control (CDC). Body mass Index: BMI for children and teens.2000.apps.nccd.cdc.gov/dnpabmi.

Centers for Disease Control and Prevention.2003: National Diabetes Fact Sheet: General Information and National Estimates on Diabetes in the United States,.Rev.ed.

Cho YM, Kim M, Park KS, Kim SY, Lee HK . 2003 S20G mutation of the amylin gene is associated with a lower body mass index in Korean type 2 diabetic patients. Diabetes Res. Clin. Pract.; 60 (2): 125-129.

Cotran, Kumar, Collins; Robbins .1999. Pathologic Basis of Disease, Saunders Sixth Edition,; 913-926.

Elizabeth R. Pulgaron, PhD and Alan M. Delamater, PhD .2014. Obesity and Type 2 Diabetes in Children.Epidemiology and TreatmentCurrDiab Rep. Aug; 14(8): 508.

Florez JC, Hirschhorn J, Altshuler D. 2003.The inherited basis of diabetes mellitus: implications for the genetic analysis of complex traits. Annu Rev Genomics Hum Genet; 4:257291.

Froguel P. 2005. ACDC/adiponectin and PPAR-gamma gene polymorphisms: implications for features of obesity, Obes. Res. , vol.13 (pg. 2113-2121)

Ganda,0. P. and Soeldner1987. Genetic, acquired and related factors in the aetiology of diabetes mellitus. Arch Intern. Med.,137: 461469.

Geetha A., Gopalakrishnan S., Umadevi R. 2017. Study on the impact of family history of diabetes among type 2 diabetes mellitus patients in an urban area of Kancheepuram district, Tamil Nadu .Int J Community Med Public Health. 4(11):41514156.

Gibson G. 2011. Rare and common variants: twenty arguments. Nat Rev Genet. ;13:135-145.

Holly J. Kramer, MD, MPH; Quan Dong Nguyen, MD, MSc; Gary Curhan, MD, ScD; et alChi-yuan Hsu, MD, MSc. 2003. Renal Insufficiency in the Absence of Albuminuria and Retinopathy Among Adults With Type 2 Diabetes Mellitus JAMA. ;289(24):3273-3277.

Jung-Nan Wei, PhD; Fung-Chang Sung, PhD; Chau-Ching Lin, MD; et alRuey-Shiung Lin, MD, DrPH;Chuan-Chi Chiang, $\mathrm{PhD}$;Lee-Ming Chuang, MD, PhD. 2003. National Surveillance for Type 2 Diabetes Mellitus in Taiwanese Children JAMA.; 290 (10):1345-1350.

Kiess W, Böttner A, Raile K, Kapellen T, Müller G, Galler A, Paschke R \&tWabitsch M. 2003. Type 2 diabetes mellitus in children and adolescents: a review from a European perspective. Horm Res; 59 suppl1:77-84.

Lazar M.A. 2006.The humoral side of insulin resistance. Nat. Med., vol.12(pg. 4344)

Le Stunff C, Fallin D, Bougnères P.2001. Paternal transmission of class I INS VNTR alleles predisposes to childhood obesity. Nat Genet 29 :96 -99. 
Lyssenko V, Jonsson A, Almgren P, et al. 2008. Clinical risk factors, DNA variants, and the development of type 2 diabete. The New England Journal of Medicine; 359 (21): 2220-32.

National Diabetes Information Clearinghouse (NDIC) National Institute of Diabetes and Digestive and Kidney Diseases, NIH). 2008. http://www.diabetes.niddk.nih.gov/dm/pubs/mody/. Retrieved.

Neel JV.1962. Diabetes mellitus: a'thrifty genotype rendered detrimental by 'progress'? Am J Hum Genet14 :353 -362.

Nina E. Berentzen,Alet H. Wijga,Lenie van Rossem, Gerard H. Koppelman,Bo van Nieuwenhuizen,Ulrike Gehring,Annemieke M. W. Spijkerman, Henriëtte A. Smit Family history of myocardial infarction, stroke and diabetes and cardiometabolic markers in children Diabetologia August 2016, Volume 59, Issue 8, pp 1666-1674

Patel M, Patel IM, Patel YM, Rathi SK. 2013. A hospitalbased observational study of type 2 diabetic subjects from India. Int J Clin Pract.; 24(2):141-8.

Papazafiropoulou AK, Papanas N, Melidonis A, Maltezos E. 2017. Family History of Type 2 Diabetes: Does Having a Diabetic Parent Increase the Risk? Curr Diabetes Rev. ;13(1):19-25

Omar, Ali. 2013. Genetics of type 2 diabetes World J Diabetes. Aug 15; 4(4): 114-123.

Reinehr Thomas. 2013. Type 2 diabetes mellitus in children and adolescents. World J Diabetes. Dec 15; 4(6): 270-281.

Ritenbaugh C, Goodby CS. 1989. Beyond the thrifty gene: metabolic implications of prehistoric migration into the New World. Med Anthropol 11 :227 -223.

Rother KI. 2007. Diabetes treatment-bridging the divide. The New England Journal of Medicine 356: (15): 1499-501.

Sakagashira S, Sanke T, Hanabusa T, et al. 1996 . Missense mutation of amylin gene (S20G) in Japanese NIDDM patients. Diabetes; 45 (9): 1279-81.
Shaw, J.T.E., Purdie, D.M., Neil, H.A.W., Levy, J.C., Turner, R.C. 1999. The relative risk of hyperglycemia, obesity and dyslipidaemia in the relatives of patients with type-II diabetes mellitus. Diabetologia; 42: 27-37.

Srikanth E. 2015. Familial Aggregation of Type 2 Diabetes Mellitus in Rural India. IJSR.:4(8):41-5. 17.

Tanko L.B., Siddiq A., Lecoeur C. Larsen P.J.Christiansen C., Walley A., Tillil H, Köbberling J. 1987. Age-corrected empirical genetic risk estimates for first-degree relatives of IDDM patients. Diabetes.; 36:93-99.

The Expert Committee on the Diagnosis and Classification of Diabetes Mellitus .2003. From the American Diabetes Association, Alexandria, Virginia Diabetes Care; 26:S5S20.

Vasseur F., Helbecque N., Lobbens S., Vasseur-Delannoy V., Dina C., Clement K., Boutin P., Kadowaki T., Scherer P.E., Froguel P. 2005. Hypoadiponectinaemia and high risk of type 2 diabetes are associated with adiponectin-encoding (ACDC) gene promoter variants in morbid obesity: evidence for a role of ACDC in diabesity, Diabetologia, vol. 48 (pg. 892-899)

Vasseur F. Lepretre F., Lacquemant C., Frogue 1P. 2003. The genetics of adiponectin, Curr. Diab. Rep., vol.3 (pg. 151-158).

World Health Organization Study Group on Diabetes Mellitus. 1985. Technical Report Series, 727, WHO Geneva,

World Health Organization. 1998. Obesity: preventing and managing the global epidemic. Report of a WHO consultation on Obesity, Geneva, 3-5, June 1997. World Health Organization: Geneva.

Yanyan Zhao, Chunhua Song, Xiaokun Ma,Xiaojun Ma, Qingzhu Wang, Hongfei Ji, Feng Guo, and Guijun Qin Synergistic. 2017 Effect of Family History of Diabetes and Dietary Habits on the Risk of Type 2 Diabetes in Central China International Journal of Endocrinology., 8 pages 